\title{
Diode Laser Excision of Blandin-Nuhn Mucocele
}

\author{
Domenico De Falco $^{1}$, Daniela Di Venere ${ }^{1}$, Eugenio Maiorano ${ }^{2}$ \\ 1. Dentistry, University of Bari Aldo Moro, Bari, ITA 2. Department of Emergency and Organ Transplantation, \\ University of Bari Aldo Moro, Bari, ITA
}

Corresponding author: Domenico De Falco, defalcodomenico@ymail.com

\begin{abstract}
The glands of Blandin and Nuhn are mixed mucous and serous glands that are embedded within the musculature of the anterior tongue ventrum. The differential diagnosis for lesions in that area is often challenging and includes other salivary and nonsalivary lesions. This affects decision-making, surgical management, and measures to prevent complications. Unlike conventional cold blade surgery, diode laser use may simplify such treatment.
\end{abstract}

Categories: Dentistry

Keywords: minor salivary glands, blandin-nuhn glands, diode laser, oral surgery

\section{Introduction}

Blandin and Nuhn mucoceles (BNMs) are rare benign lesions, which develop on the ventral side of the tongue in newborns as well as pediatric and adult patients [1,2]. These lesions are frequently misdiagnosed as conventional mucoceles or ranulas [1-3]. Despite the small size of Blandin and Nuhn glands (8 $\mathrm{mm}$ wide and 12-25 mm deep), BNMs can sometimes have large dimensions [4]. Nevertheless, their management with marsupialization is not recommended, leaving surgical excision as the treatment of choice $[5,6]$. Conventional surgery (scalpel and stitches) may create discomfort, especially in children, as it can involve intraoperative bleeding, postsurgical edema, and related difficulties in chewing and swallowing. Diode laser surgery is characterized by a lack of bleeding during cutting, reduction of postoperative edema, absence of unnecessary stitches, and fast mucosal healing, and therefore represents a superior treatment option for BNMs [7].

\section{Case Presentation}

A 28-year-old female was referred to us for the management of a persistent lesion on the floor of the mouth. Intraoral examination showed a red-brown firm, painless, and round lesion of the ventral tongue that had been present for six months (Figure 1A). Diode laser-assisted excision was suggested, and the patient agreed to the procedure. With minimal local infiltration of anesthesia, the lesion was surgically removed using a diode laser with a wavelength of $800 \pm 10 \mathrm{~nm}$, in continuous modality, and with an output energy of $1.5 \mathrm{~W}$ (Figure 1B); no intraoperative bleeding was observed and stitches were unnecessary. Histological examination revealed a cystic lesion containing mucin with a surrounding epithelial lining, consistent with a

Received 03/20/2020 Review began 03/24/2020 Review ended 03/26/2020 Published 03/28/2020

\section{(๑) Copyright 2020}

De Falco et al. This is an open access article distributed under the terms of the Creative Commons Attribution License CC-BY 4.0., which permits unrestricted use, distribution, and reproduction in any medium, provided the original author and source are credited. diagnosis of BNM (Figure 1C). The surgical wound healed completely in 12 days.
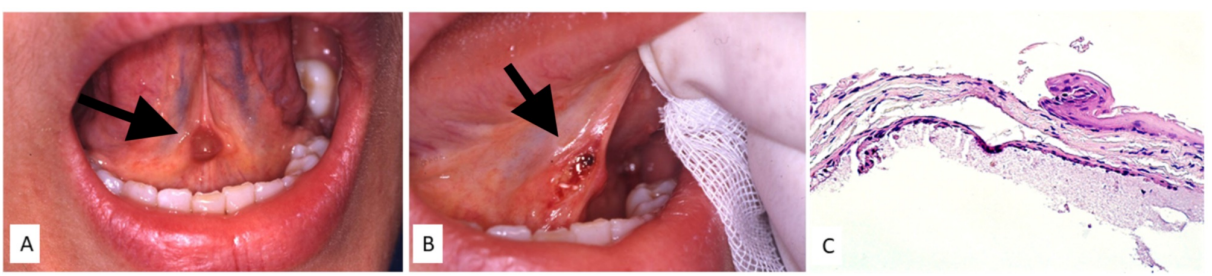

FIGURE 1: Red-brown lesion of the ventral tongue (A) surgically removed by diose laser without bleeding or unnecessary stitches (B); histological examination showing a thin epithelial lining with foci of extravasation containing mucin (C).

\section{Discussion}

The Blandin-Nuhn glands are a small group of mixed mucous and serous salivary glands, with five to seven small duct openings in the oral cavity, situated on the midline of the ventral tongue $[1,2,8]$. Although BNMs are commonly described as uncommon lesions, several reports exist in the literature [5]. They typically require invasive surgical management, which may be associated with postoperative complications $[2,4,5]$. 
The introduction of laser therapy as a treatment option, with reduced bleeding and postoperative edema, absence of unnecessary stitches, and fast mucosal healing, represents a useful innovation in oral surgery such as the excision of benign and malignant neoplasms, surgical or nonsurgical periodontal treatment, decontamination, management of gingival overgrowth, and photocoagulation of oral cavity venous malformations [7,9-12]. As reported in this case, laser diode intervention appears to be less invasive than conventional surgery with cold blade excision and stitches, and it would be particularly preferable in newborns and uncooperative children, with increased acceptability of the procedure by parents.

\section{Conclusions}

Surgical removal of proliferating lesions of the ventral tongue may represent a challenge for the surgeon, especially in uncooperative patients. The highlighted advantages of the surgical removal by diode laser, especially less amount of local anesthesia, rapidity, lack of bleeding and no suture, unlike conventional scalpel surgery, may surely simplify the procedure itself as well improve patient compliance. In addition, the uncomplicated postoperative course with minimal or completely absent pain and edema further improves the overall clinical benefits of diode laser surgery.

\section{Additional Information \\ Disclosures}

Human subjects: Consent was obtained by all participants in this study. Conflicts of interest: In compliance with the ICMJE uniform disclosure form, all authors declare the following: Payment/services info: All authors have declared that no financial support was received from any organization for the submitted work. Financial relationships: All authors have declared that they have no financial relationships at present or within the previous three years with any organizations that might have an interest in the submitted work. Other relationships: All authors have declared that there are no other relationships or activities that could appear to have influenced the submitted work.

\section{References}

1. Graillon N, Mage C, Le Roux MK, Scemama U, Chossegros C, Foletti JM: Mucoceles of the anterior ventral surface of the tongue and the glands of Blandin-Nuhn: 5 cases. J Stomatol Oral Maxillofac Surg. 2019, 120:509-512. 10.1016/j.jormas.2019.04.005

2. Adachi P, Soubhia AM, Horikawa FK, Shinohara EH: Mucocele of the glands of Blandin-Nuhn--clinical, pathological, and therapeutical aspects. Oral Maxillofac Surg. 2011, 15:11-13. 10.1007/s10006-010-0221-1

3. More CB, Bhavsar K, Varma S, Tailor M: Oral mucocele: a clinical and histopathological study . J Oral Maxillofac Pathol. 2014, 18:72-77.

4. de Camargo Moraes P, Bönecker M, Furuse C, Thomaz LA, Teixeira RG, de Araújo VC: Mucocele of the gland of Blandin-Nuhn: histological and clinical findings. Clin Oral Investig. 2009, 13:351-353. 10.1007/s00784009-0252-x

5. Joshi SR, Pendyala GS, Choudhari S, Kalburge J: Mucocele of the glands of blandin-nuhn in children: a clinical, histopathologic, and retrospective study. N Am J Med Sci. 2012, 4:379-383. 10.4103/19472714.100977

6. Jinbu Y, Kusama M, Itoh H, Matsumoto K, Wang J, Noguchi T: Mucocele of the glands of Blandin-Nuhn: clinical and histopathologic analysis of 26 cases. Oral Surg Oral Med Oral Pathol Oral Radiol Endod. 2003, 95:467-470. 10.1067/moe.2003.51

7. Angiero F, Parma L, Crippa R, Benedicenti S: Diode laser $(808 \mathrm{~nm})$ applied to oral soft tissue lesions: a retrospective study to assess histopathological diagnosis and evaluate physical damage. Lasers Med Sci. 2012, 27:383-388. 10.1007/s10103-011-0900-7

8. Sugerman PB, Savage NW, Young WG: Mucocele of the anterior lingual salivary glands (glands of Blandin and Nuhn): report of 5 cases. Oral Surg Oral Med Oral Pathol Oral Radiol Endod. 2000, 90:478-482.

9. Limongelli L, Tempesta A, De Caro A, et al.: Diode laser photocoagulation of intraoral and perioral venous malformations after tridimensional staging by high definition ultrasonography. Photobiomodul Photomed Laser Surg. 2019, 37:722-728. 10.1089/photob.2019.4635

10. Capodiferro S, Limongelli L, Tempesta A, Maiorano E, Favia G: Diode laser treatment of venous lake of the lip. Clin Case Rep. 2018, 22:1923-1924. 10.1002/ccr3.1735

11. Capodiferro S, Tempesta A, Limongelli L, Maiorano E, Benedicenti S, Favia G: Nonsurgical periodontal treatment by erbium:YAG laser promotes regression of gingival overgrowth in patient taking cyclosporine A: a case report. Photobiomodul Photomed Laser Surg. 2019, 37:53-56. 10.1089/photob.2018.4478

12. Limongelli L, Capodiferro S, Tempesta A, et al.: Early tongue carcinomas (clinical stage I and II): echoguided three-dimensional diode laser mini-invasive surgery with evaluation of histological prognostic parameters. A study of 85 cases with prolonged follow-up. Lasers Med Sci. 2020, 35:751-758.

10.1007/s10103-019-02932-z 